\title{
Imaging in lung cancer: positron emission tomography scan
}

\author{
J.F. Vansteenkiste
}

Imaging in lung cancer: positron emission tomography scan. J.F. Vansteenkiste. (C)ERS Journals Ltd 2002.

ABSTRACT: In the past 5 yrs, positron emission tomography (PET), usually used with ${ }^{18}$ F-fluoro-2-deoxy-glucose (FDG), has become an important imaging modality in lung cancer patients.

Currently, the use of FDG-PET in respiratory oncology is mainly for diagnosis and staging. Standard indications are the evaluation of an indeterminate solitary pulmonary nodule or mass, where FDG-PET has proven to be significantly more accurate than computed tomography (CT) in the distinction between benign and malignant lesions. Several studies have also convincingly demonstrated that locoregional lymph node staging by FDG-PET (in correlation with CT images) is significantly superior to CT, with a negative predictive value equal or even superior to mediastinoscopy. FDG-PET also improves extrathoracic staging, through the detection of lesions missed at conventional imaging or characterization of lesions that remain equivocal on conventional imaging. Many European countries now have or plan reimbursement in these indications. Large-scale randomized studies should now focus on the impact this accurate tumour imaging technique has on treatment outcome and cost-efficacy.

Ongoing studies in specialized centres focus on the use of FDG-PET in more advanced clinical applications, such as planning radiotherapy, response evaluation after radiotherapy or (induction) chemotherapy, follow-up and early detection of recurrence, and prognostic information in this in vivo measurement of tumour glucose metabolism.

After a short note on the technique used and a summary of the current common indications of diagnosis and staging, this paper will deal mainly with two of the more advanced clinical applications of FDG-PET in locally advanced nonsmall cell lung cancer: radiation treatment planning and assessment of induction chemotherapy.

Finally, it should be mentioned that a whole new field of applications of positron emission tomography in molecular biology, using new radiopharmaceutical probes, is under extensive investigation. These techniques are promising for future use in very early response monitoring during chemo- or radiotherapy, in evaluation of novel molecular-targeted lung cancer therapies, or even gene therapy.

Eur Respir J 2002; 19: Suppl. 35, 49s-60s.
Respiratory Oncology Unit (Dept of Pulmonology), University Hospital Gasthuisberg, Catholic University Leuven, Belgium.

Correspondence: J.F. Vansteenkiste Respiratory Oncology Unit (Dept of Pulmonology)

University Hospital Gasthuisberg Herestraat 49

B-3000 Leuven

Belgium

Fax: 3216346803

E-mail: johan.vansteenkiste@,

uz.kuleuven.ac.be

Keywords: Emission computed tomography

induction chemotherapy

lung neoplasms

radiotherapy planning

staging

treatment outcome

Received: June 142001

Accepted June 142001
More than 200,000 new cases of lung cancer are diagnosed in the European Union (EU) each year. This disease is by far the most common cause of cancer-related death in the EU. Due to an increase in smoking amongst females, an increase in overall incidence is to be expected well into the first decades of the 21 st century.

Conventional imaging, including chest radiography, computed tomography (CT), ultrasonography, and magnetic resonance imaging, has a major role in the diagnosis, staging, and follow-up of patients with lung cancer. Although these imaging tests allow exquisite anatomic detail, they usually do not provide a definitive diagnosis or staging. Therefore, more invasive tests with tissue sampling are often required. Positron emission tomography (PET) was initially used as a research tool for brain function studies [1,2] and the assessment of cardiac metabolism [3, 4]. In the past $5 \mathrm{yrs}$, however, $>80 \%$ of its indications have been as an innovative imaging technique in tumour patients. Different applications in lung cancer are listed in table 1.

The use of ${ }^{18}$ F-fluoro-2-deoxy-glucose (FDG)-PET in respiratory oncology is based on its ability to

Table 1.-Indications for ${ }^{18} \mathrm{~F}$-fluoro-2-deoxyglucose positron emission tomography in respiratory oncology

Common clinical indications

Evaluation of nodules and masses

Locoregional staging

Extrathoracic staging

Applications under investigation

Radiotherapy planning

Response evaluation postradiotherapy

Response evaluation post (induction) chemotherapy

Follow-up and diagnosis of recurrence

Prognostic information

Molecular applications

Early assessment of (chemo)therapy

Assessment of molecular targeted therapy 
visualize the differences between the glucose metabolism of tissues. Neoplastic cells have a much higher rate of glycolysis than non-neoplastic cells and an increased cellular uptake of glucose, probably due to an increased expression of glucose transport proteins [5-8]. FDG, a glucose analogue in which the oxygen molecule in position 2 is replaced by a positronemitting ${ }^{18}$ fluorine, undergoes the same uptake as glucose, but is metabolically trapped and accumulated in the neoplastic cell after phosphorylation by hexokinase [9-11].

Positron-emitting isotopes, such as ${ }^{18}$ fluorine, have an excess of protons and are therefore unstable. They decay by emission of a positron, which is the subatomic, positively charged, antiparticle of the negatively charged electron. The positron released in this process has kinetic energy, travels a short distance, and then annihilates with an electron. This annihilation creates two $511 \mathrm{keV}$ photons, emitted in opposite directions. The detection of high numbers of these annihilations by the detector rings of the PET camera generates high-resolution pictures $(5-10 \mathrm{~mm})$ indicating the sites of FDG accumulation in the body [12]. The preferential accumulation of FDG in neoplastic cells permits differentiation between benign and malignant tissue. In this way, FDG-PET compliments the anatomic information on standard imaging with metabolic information.

\section{Technical aspects}

\section{The different acquisition protocols}

Whole-body images are most commonly used for clinical oncology studies. In this technique, FDG is injected into the patient outside the PET camera. After an uptake period of $1 \mathrm{~h}$, necessary to obtain a good tumour-to-normal tissue contrast, the patient is positioned in the camera. Since the field of view of the PET camera is only $10-15 \mathrm{~cm}$, different bed positions need to be scanned to obtain a whole-body survey. At the end, the data of the different bed positions are reconstructed to a whole-body image by a computer algorithm, taking into account the physical decay of the FDG tracer during the examination. The advantage of this technique is that it allows a fast acquisition (usually $<45 \mathrm{~min}$ ) of information of the whole body. The disadvantage is that since no attenuation correction is performed, the technique only generates images for visual interpretation, without any quantitative information on FDG-uptake.

Attenuation-corrected images are needed in order to gain more information on FDG uptake. An important number of the emitted photons are absorbed in the patient's body. This absorption depends on the position in the body (e.g. superficial lesions are less attenuated than those situated in deeper layers of the body) and the type of surrounding tissue (e.g. lung tissue is less attenuating than muscle tissue). Since the intensity of the photon emission of a lesion is position dependent, the intensity seen on the nonattenuation corrected whole-body images does not truly reflect the actual FDG uptake. If the images are corrected for photon attenuation by a so-called transmission scan, which estimates the attenuating characteristics of the patient, quantification of the FDG metabolism becomes possible. This transmission scan, which can be performed prior to ("cold transmission") or after ("hot transmission") FDG injection, prolongs the acquisition time substantially. In addition, the use of the transmission scan allows the Standardized Uptake Value (SUV) to be reported. The SUV of a lesion is a semiquantitative index of the glucose utilization that is obtained by normalizing the accumulation of FDG in the lesion to the injected dose and patient body weight [13].

Initially, the transmission scan to correct for photon attenuation could only be performed prior to FDG injection (cold transmission). After FDG injection, the patient had to remain completely still in the PET camera for $\sim 1 \mathrm{~h}$, the time needed to obtain a good tumour-to-normal tissue contrast. Acquisition of the emission images, usually limited to two or three bed positions, and whole-body images then completed the examination. A total camera time of nearly $3 \mathrm{~h}$ was needed for the entire sequence. With the introduction of hot transmission (i.e. acquisition of transmission images after injection, and alternating with emission images) to the new PET devices and the development of new reconstruction methods to decrease transmission time, whole-body attenuation corrected images can now be obtained in 60-80 min $[14,15]$.

\section{Methods to facilitate the more widespread availability of ${ }^{18}$ F-fluoro-2-deoxy-glucose positron emission tomography imaging}

Several factors actually impede the widespread use of FDG-PET as a tool complimentary to CT in the diagnosis and staging of nonsmall cell lung cancer (NSCLC). However, further development of the technique can be expected when commercial isotope distributors will be able to deliver FDG, so that an onsite cyclotron is no longer needed. FDG has a half-life of $110 \mathrm{~min}$, so a practical distribution radius of $200-300 \mathrm{~km}$ should be feasible.

Another factor will be the availability of PET cameras. Whether cheaper dual-head gamma camera coincidence imaging (GCI) will be a valid substitute is still uncertain and requires a large amount of carefully controlled clinical studies. Indeed, conclusions on the use of FDG-PET in respiratory oncology are mainly based on studies using high-performance PET cameras (so-called dedicated PET scans), characterized by high resolution and sensitivity. Because of the high cost of a dedicated PET camera, GCI has been examined as a potential alternative. However, the crystals used in these gamma cameras have less stopping power for high energy photons compared to those used in dedicated systems, which results in a decrease in positron emission detection and thus, sensitivity [16]. Some studies have already compared GCI with dedicated PET in lung cancer, in a limited number of cases, ranging from 23-31 patients [17-20]. Some series, which usually included larger lesions 
visible on both techniques, suggested that both techniques are equivalent. In a more challenging study, GCI detected $13(93 \%)$ of the 14 lung nodules, 20 $(65 \%)$ of the 31 metastatic mediastinal nodes, and only $27(42 \%)$ of the 64 distant metastases seen on PET [20]. Another study found an $86 \%$ overall accuracy in staging lung cancer with FDG-PET, compared to only $64 \%$ with GCI [19]. This suggests that the sensitivity of GCI clearly decreases for lesions $<2 \mathrm{~cm}$. Obviously, this affects the detection of small metastatic deposits in mediastinal nodes or distant sites. Care should therefore be taken when extrapolating the conclusions on clinical decision-making obtained with dedicated PET in a situation where GCI is used.

\section{Common clinical indications}

The standard clinical indications for FDG-PET imaging in lung cancer patients have been detailed in a recent review [21]. In this contribution, these indications will only be repeated briefly, with emphasis on clinical application.

\section{Diagnosis of solitary lung nodule or mass}

The problem of differential diagnosis of an indeterminate solitary pulmonary nodule is well known. Calcification or absence of growth over a 2 -yr period are highly suggestive of a benign lesion, but calcification or comparator chest radiographs are usually lacking $[22,23]$. Bronchoscopy is often nondiagnostic and a transthoracic needle-aspiration biopsy has complications, such as pneumothorax, requiring drainage in $5-10 \%$ of the procedures [24], and possible false-negative findings, leading to an unacceptable expectation in patients with early-stage lung cancer $[25,26]$.

FDG-PET has thus been studied extensively as a promising noninvasive imaging test to differentiate between benign and malignant nodules [27-37]. Based on 12 well-designed prospective studies, it can be concluded that FDG-PET has proven to be accurate in differentiating benign from malignant lesions as small as $1 \mathrm{~cm}$ [21]. An overall sensitivity of $96 \%$ (range $83-100)$, specificity of $79 \%(52-100)$ and accuracy of 91\% (86-100) can be expected.

Potential pitfalls in sensitivity are due to the fact that a critical mass of metabolically active malignant cells is required for PET diagnosis. Therefore, falsenegative findings can occur in lesions $<1 \mathrm{~cm}[29,30$, $34,35,38]$, in tumours with low metabolic activity (e.g. carcinoid tumours $[30,39])$, or in bronchioloalveolar cell carcinoma [38, 40-42].

Errors in specificity are due to FDG uptake in inflammatory conditions, such as bacterial pneumonia [43], pyogenic abscess or aspergillosis, granulomatous diseases, active sarcoidosis [44], tuberculosis, histoplasmosis, coccidiomycosis, Wegener's disease or coal miner's lung. In these lesions, the FDG uptake has been attributed to an increase in granulocyte and/or macrophage activity [45].

\section{Locoregional lymph node staging}

The lymph node (LN) extension in NSCLC determines the prognosis and the choice of treatment. Indeed, patients without malignant $\mathrm{LNs}_{\mathrm{N}}$ in the mediastinum are usually treated with straightforward surgical resection. Patients with diseased mediastinal LNs are candidates for induction chemotherapy, followed by surgery and/or radiotherapy [46-50]. It is therefore of considerable clinical interest to evaluate these mediastinal LNs as accurately as possible.

CT is the most commonly used noninvasive staging method of the mediastinum, but is far from satisfying and less accurate than invasive surgical staging [51-54]. In prospective data from the Radiological Diagnostic Oncology Group, the sensitivity and specificity of thoracic CT were only 52\% and $69 \%$ [55]. The Leuven Lung Cancer Group (LLCG) found that the best results were obtained when $\mathrm{LNs} \geqslant 1.5 \mathrm{~cm}$ at their maximal cross-sectional diameter were considered to be metastatic [56]. Using this criterion, the sensitivity was $69 \%$ and the specificity $71 \%$. Because of this very moderate level of accuracy of CT, invasive staging by mediastinoscopy until recently remained the only reliable tool for mediastinal LN staging. The use of FDG-PET as a noninvasive tool for the determination of LN spread has thus been examined in several well-designed prospective studies [27, 57-72]. FDG-PET proved to be significantly more accurate than $\mathrm{CT}$ in locoregional $\mathrm{LN}$ staging. In the distinction between presence (N2-N3) or absence (N0-N1) of mediastinal LN disease, an overall sensitivity of $89 \%(67-100)$, a specificity of $92 \%(79-100)$ and an accuracy of $90 \%(78-100)$ can be expected for FDG-PET, in contrast with a sensitivity of $65 \%$ (20-86), a specificity of $80 \%(43-90)$, and an accuracy of $75 \%(52-79)$ for CT [21]. The superiority of FDG-PET can be explained by the fact that the size of LNs on CT is a relative criterion; FDG-PET correctly identifies small malignant nodes and large benign nodes.

False-negative findings can occur when the tumour deposit in the mediastinal nodes is small, especially in so-called "minimal N2", where a reasonable prognosis after surgical resection can be expected [73]. False-positive images are possible in LNs containing anthracosilicosis [32] or inflammatory tissue with high metabolic activity. Therefore, the use of mediastinoscopy is still advised to prove $\mathrm{N} 2$ or $\mathrm{N} 3$ disease in patients with positive mediastinal nodes on PET. Mediastinal mapping by mediastinoscopy is justified before the start of a chemotherapy induction protocol and is needed to ensure that no single patient with N0 or N1 disease is denied the chance of cure by direct surgical resection based on a false-positive PET.

\section{Extrathoracic staging}

Patients with extrathoracic metastases are no longer amenable to long-term remission or cure. It should be realized that current standard staging based on clinical and biological factors and imaging tests, such as CT, ultrasound, or bone scintigraphy [74, 75], is far 
from perfect. After radical treatment for apparently localized disease, $\sim 20 \%$ of the patients will nonetheless have an early distant relapse [76-78], due to micrometastases already present at the time of initial staging [79], usually in the adrenal glands, bones, brain, or liver [80].

Most organ-specific studies on the detection of distant metastases in lung cancer patients do not have the power of locoregional staging studies. For bone metastasis, one study found an equivalent sensitivity of FDG-PET and standard bone scintigraphy, but a much higher specificity for FDG-PET (98\% versus 61\%) [81]. Another study indicated that FDG-PET was more sensitive than bone scintigraphy and allowed better differentiation between benign and malignant lesions [82].

Adrenal masses, which are found in $\leqslant 20 \%$ of NSCLC patients at initial presentation [83-85], are often a diagnostic challenge. FDG-PET can be a useful adjunct to other imaging modalities. Some small series highlight the high sensitivity of FDG-PET in the detection of adrenal metastases [86-88]. An equivocal lesion on CT without FDG uptake on PET will usually not be metastatic, but care should be taken in the interpretation of small lesions. With regard to FDG-positive adrenal lesions, pathological proof by, for example, puncture needs to be obtained before a decision about inoperable disease is made [86].

In the evaluation of liver metastasis, the main advantage of FDG-PET is its ability to differentiate between hepatic lesions that were not determined by conventional studies. In one study, FDG-PET accurately indicated liver metastases in two patients with negative conventional imaging and in nine with equivocal findings on conventional liver imaging. In addition, FDG-PET could exclude metastasis in four cases with suspect conventional imaging [89].

FDG-PET can also reveal metastases that otherwise escape clinical detection, e.g. small nodules in the other lung, soft tissue lesions, retroperitoneal LNs, hardly palpable supraclavicular LNs, etc. Because whole-body FDG-PET is able to stage both intra- and extrathoracic sites in one examination and because it is more accurate than conventional imaging, it is reported to change patient management in $19-41 \%$ of patients [58, 90-93].

Although numerous data indicate that FDG-PET can complement conventional imaging in the detection of extrathoracic metastases, there is clearly insufficient data to suggest that FDG-PET can replace it. In contrast with the large amount of data on locoregional staging, most of the organ-specific studies are small and do not include an adequate number of small lesions, which really challenge the technique.

\section{Use of ${ }^{18}$ F-fluoro-2-deoxy-glucose positron emission tomography in radiotherapy planning}

Most of the FDG-PET studies of locoregional NSCLC staging were performed or implemented in a pre-operative setting. However, FDG-PET could be of equivalent interest in radiotherapy planning in nonmetastatic patients not suitable for surgery (e.g. due to cardiopulmonary limitations or contralateral LN disease). Exact definition of the locoregional tumour load will not only influence the treatment intention, i.e. curative or palliative dose, but also the treatment volume and, therefore, the toxicity. Several studies have suggested an important relationship between the irradiated volume and the likelihood of radiation pneumonitis [94-97]. Different parameters from dose/volume histograms have been correlated with the incidence of radiation pneumonitis, e.g. the percentage of the lung volume receiving more than 20 Gy (Vlung20) [94]. The ability of these parameters to predict the rate of pneumonitis and to guide dose escalation protocols is currently under investigation in prospective studies [98, 99].

Classical radiotherapy planning uses conventional imaging, such as chest radiography and CT, to describe the tumour and to draw the target volume for irradiation. The main limitations of this method are the poor demarcation of some tumours on CT and the inability of CT to distinguish between benign and malignant LNs. FDG-PET might help to limit the volume of normal tissues irradiated in patients, in whom the FDG-PET-defined locoregional tumour spread is smaller than the CT-defined locoregional tumour spread. It might also help to reduce geographical misses outside the radiation fields, in patients in whom the FDG-PET-defined locoregional tumour spread is more extensive than the CT-defined locoregional tumour spread.

One study reported on the additional information generated by FDG-PET in 12 patients with poorly demarcated tumours. CT and FDG-PET volumes corresponded in seven patients, but in three, the CT abnormalities were larger than on FDG-PET, and in two, the abnormalities on FDG-PET extended outside the region of CT changes [100]. Another retrospective study highlighted the substantial reduction in radiation fields by FDG-PET, especially in postobstructive atelectasis [101]. Due to the occurrence of this in 34 patients, it was concluded that in 10 of 34 cases the size of the treatment field could have been reduced.

With regard to the involvement of LNs, a theoretical study on the potential impact of FDG-PET on the radiation treatment plan of NSCLC patients was carried out at the author's centre [102]. The imaging and surgical pathology data from 105 patients included in two previously published prospective LN staging protocols were used for the analysis [59, 61]. The main advantage of this approach was that invasive surgical staging of 988 LN stations from 105 patients was available, so that the gold standard of pathological information could be used to interpret the radiotherapy study findings.

A theoretical plan was made for 73 patients who had positive LNs present on CT and/or FDG-PET. For each patient, the irradiated volume (gross tumour volume (GTV)) was defined based on CT and FDGPET (correlated with CT) images. For each GTV, the completeness of tumour coverage was assessed, using the available surgical pathology data as gold standard (table 2). A GTV based on the tumour and LNs 
Table 2. - Number of patients achieving or not achieving complete tumour coverage by the radiation field as defined either on computed tomography (CT) or positron emission tomography (PET) (adapted from [102])

\begin{tabular}{lcclcc}
\hline & \multicolumn{2}{c}{ CT } & & \multicolumn{2}{c}{ PET } \\
\cline { 2 - 3 } \cline { 5 - 6 } & Ncovered & Nnoncovered & & Ncovered & Nnoncovered \\
\hline PET $<$ CT & 26 & 3 & & 25 & 4 \\
PET $>$ CT & 1 & 15 & & 12 & 4 \\
PET $=$ CT & 28 & 0 & & 28 & 0 \\
Totals & 55 & 18 & & 65 & 8 \\
\hline
\end{tabular}

Ncovered: number of patients with complete coverage of the tumour by the radiation field; Nnoncovered: number of patients with incomplete coverage of the tumour by the radiation field. PET $<\mathrm{CT}$ : tumour extension on PET smaller than on CT; PET $>\mathrm{CT}$ : tumour extension on PET larger than on CT; PET $=\mathrm{CT}$ : tumour extension on PET identical to CT.

judged to be positive on CT alone would have covered all pathological nodes in 55 of 73 patients $(75 \%)$. In addition, using FDG-PET data, coverage of pathological LNs would have been present in 65 patients $(89 \%, p=0.0005)$. The CT-defined volume was identical to the FDG-PET-defined volume in 28 patients, leaving 45 patients $(62 \%)$ in whom the additional acquisition of FDG-PET data changed treatment volumes. In 16 patients $(22 \%)$, the FDG-PET-defined volume was larger. In 11 of these, this was proved to be correct by the surgical pathology data, and in the other five, the enlargement was unnecessary in one and still insufficient in four. In 29 patients (40\%), the FDG-PET-defined volume was smaller than the CT-defined volume: in 25 cases, this reduction was correct, as the FDG-PET-defined volume covered all pathological nodes; in one patient, the reduction was inappropriate; and in three patients, both the FDGPET- and the CT-defined volumes were too small. Therefore, according to the pathology data, this change of volume was correct in 36 patients $(49 \%)$, inappropriate in two (3\%) and insufficient in seven $(10 \%)$. Insufficient correction of the radiotherapy volumes was either due to $\mathrm{LN}$ stations with only minimal-N2 disease [73] or localization errors between adjacent nodes (e.g. lower right tracheobronchial level (4R) and subcarinal (7) levels).

A more detailed analysis was performed for 10 consecutive patients in whom the PET-GTV was smaller than the CT-GTV. For these patients, theoretical radiation treatment plans were constructed based on both CT-GTV and PET-GTV. Dose/volume histograms for target volume planning, the total lung volume, and the Vlung20 were calculated. The dosimetry study in these 10 patients showed an average reduction in the planning target volume of $29 \pm 18 \%$ $( \pm 1 \mathrm{SD})(\mathrm{p}=0.0002)$, with a maximum of $66 \%$ in one patient, when the additional information from FDGPET was implemented. For Vlung20, a decrease of $27 \pm 18 \%( \pm 1 \mathrm{SD})(\mathrm{p}=0.001)$ was found, with a maximum of $59 \%$ in one patient. A typical example is shown in figure 1.

Based on these findings, it was concluded that the use of locoregional LN staging by FDG-PET
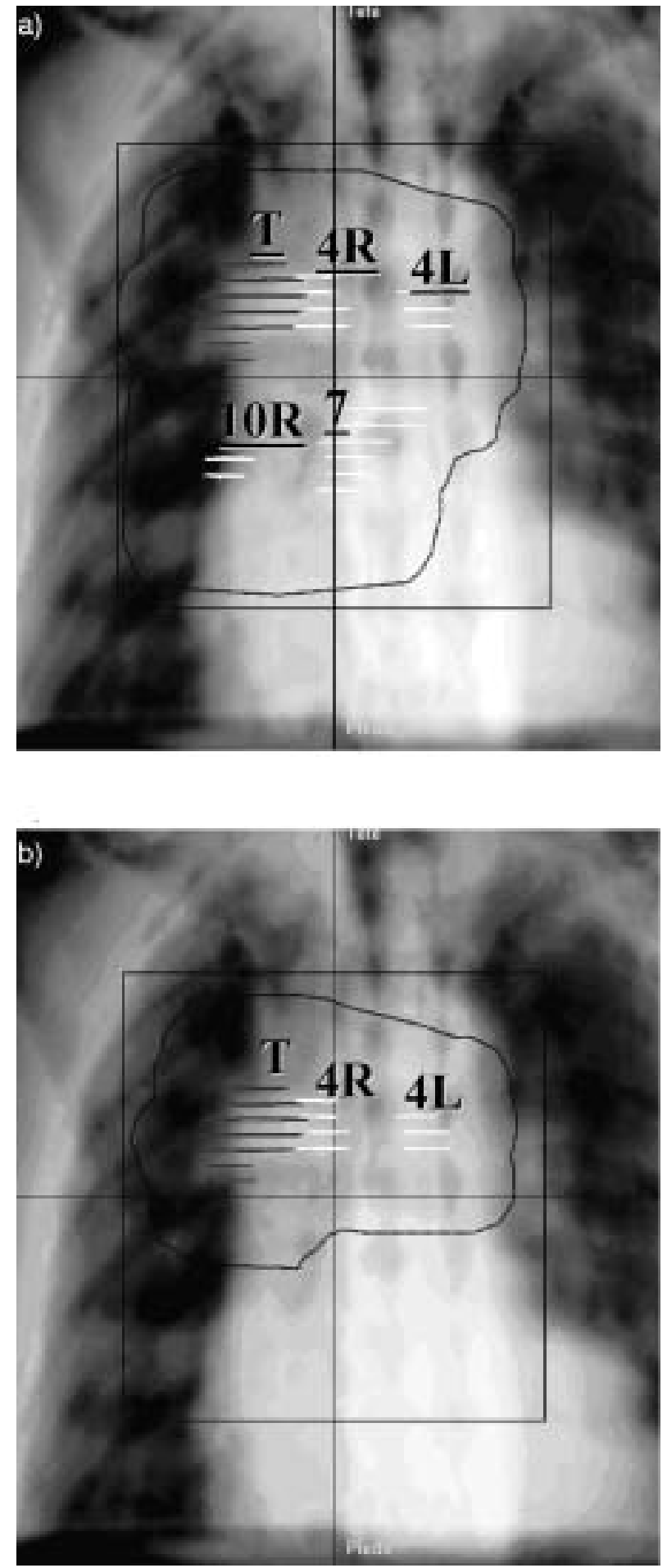

Fig. 1.- Illustration of the reduction of the radiation treatment volume when using ${ }^{18}$ F-fluoro-2-deoxy-glucose positron emission tomography (FDG-PET). According to a) computed tomography, malignancy is located in a right upper lobe tumour $(T)$, the right hilar nodes $(10 \mathrm{R})$, the right $(4 \mathrm{R})$ and left $(4 \mathrm{~L})$ lower paratracheal nodes, and the subcarinal ones (7). b) FDG-PET correctly excluded lymph node disease in stations 7 and $10 \mathrm{R}$. This reduced the treatment volume by $37 \%$.

substantially improved tumour coverage in some patients. It also reduced treatment volumes in other patients, leading to a reduced volume of irradiated 
normal tissue, and therefore a reduced toxicity, and the opportunity for treatment intensification.

Other groups have reported on the feasibility of using FDG-PET information in modern radiotherapy. $\mathrm{CT}$ and FDG-PET lung image registration and fusion, based on the chamfer-matching method, could be validated in both anatomic thoracic phantom images and clinical patient images [103]. Detailed analysis in five patients indicated a small spatial error $(<4 \mathrm{~mm})$ in the coregistration. The authors concluded that coregistration systems could facilitate target definition and treatment planning. Another study came to a similar conclusion for CT and GCI images [104]. Three-dimensional (3D) fusion of these images was used for virtual simulation in 12 patients, using four landmarks drawn on the patient's skin. Again, matching error was small $(<5 \mathrm{~mm})$. Anatometabolic fusion corrected LN staging in four individuals and extrathoracic staging in one. In these patients, the dose/ volume histograms revealed a reduction in Vlung20 by an average of $23 \%$.

Two retrospective studies examined the utility of FDG-PET during CT-based radiation treatment planning. In one, it was reported that FDG-PET data influenced $34 \%$ (12 of 35) of the treatment plans examined and resulted in enlarged portions of the beam aperture (margins of tumour spread), $\leqslant 15 \mathrm{~mm}$ [105]. In the other, the influence of viewing coronal thoracic FDG-PET images at the time of radiotherapy planning on the anterior-posterior treatment fields of 15 nonoperated patients was assessed [106]. It found that four of 15 patients $(27 \%)$ would have had different treatment volumes based on complimentary FDG-PET information.

Modern radiotherapy in NSCLC uses 3D conformal techniques and dose escalation, which shows irradiation of gross disease only, thereby eliminating the elective nodal irradiation in an attempt to minimize the volume of normal tissues irradiated and keep toxicity within acceptable levels [107]. When this type of planning is intended, the mediastinal tumour spread should be known as precisely as possible in order to avoid, on the one hand, geographical misses and, on the other, to maximally reduce the volumes of normal tissues irradiated. Future prospective comparative studies are clearly shown to determine the best use of FDG-PET in this setting and its potential advantages in terms of reduced toxicity, treatment intensification, better local control and increased survival.

\section{Assessment of response after induction chemotherapy}

If the mediastinoscopy in potentially operable NSCLC patients is positive for N2 disease, the results of direct surgical resection (or radiotherapy) are very disappointing [73, 108-110], mainly due to systemic relapses [111]. Effective systemic therapy (induction chemotherapy (IC)), followed by resection with mediastinal dissection, is probably a better treatment option for these patients $[46-50,112]$. In these treatment regimes, it is well known that clearance of viable tumour cells in the mediastinum (downstaging) and pathological response in the primary tumour, are very important for prognosis [113-118]. In US data, the estimated 5-yr survival rate of patients with a pathological complete response (pCR) was 54\%, while it was only $15 \%$ in those without pCR [119].

The presence of downstaging and primary tumour response is usually assessed in the resection specimen post surgery. Ideally, however, this information should be available pre-operatively, in order to select the patients with downstaging or good pathological response for radical surgery with mediastinal dissection and to avoid this major treatment in those unlikely to benefit. CT has not been proven to be a good tool for this purpose. It is well known that patients with little decrease in measurements on the CT can nonetheless have mediastinal LN downstaging or primary tumour response, while those with important decrease can still have metastatic LNs or viable tumour. However, re-mediastinoscopy after induction is often difficult or incomplete, due to fibrosis caused by the chemotherapy and by extensive sampling during the first mediastinoscopy.

Based on favourable experience with FDG-PET in initial LN staging in NSCLC at diagnosis [59, 62], a prospective protocol was started in 1996 to assess cisplatin-based IC in stage IIIA-N2 NSCLC. The specific question to be studied concerned whether FDG-PET after IC would be more reliable than CT in the evaluation of mediastinal LN downstaging, and if some FDG-PET findings would be predictive for outcome after the entire combined modality therapy. The results of the pilot project have been published recently [120]. Fifteen patients were examined. They all had a negative standard staging for extrathoracic metastases [75] and surgically proven IIIA-N2 NSCLC. Patients were treated with three cycles of IC, consisting of the standard LLCG schedule at that time, based on vindesine, ifosfamide and cisplatin [121]. Evaluation of response after IC on CT was carried out according to standard response criteria [122] and patients without enlarged LNs on CT were considered to have LN downstaging. Responding patients went on to surgery with $\mathrm{LN}$ dissection or radical radiotherapy ( 25 to 33 fractions of 2 Gy) in cases with insufficient cardiopulmonary fitness. In patients without a clear response, radiotherapy for consolidation usually consisted of 13-17 fractions of $3 \mathrm{~Gy}$.

FDG-PET images were acquired before and after IC. The images pre- and post-IC were interpreted prospectively, blinded to surgical pathology data and used for study purpose only. Patients with FDG uptake in the mediastinum that was not higher than mediastinal blood pool activity, were considered to have LN downstaging. The response of the primary tumour was expressed as the per cent decrease in its SUV, according to the formula 100-(SUVpost/ SUVpre $\times 100$. Primary tumour response on FDGPET was defined as a drop of $\geqslant 50 \%$ in SUV.

CT correctly predicted mediastinal LN downstaging in six of nine operated cases, but erroneously suggested downstaging in one and persistence of metastatic mediastinal nodes in two. FDG-PET, in contrast, was correct in all instances.

FDG-PET was also superior in determining the 

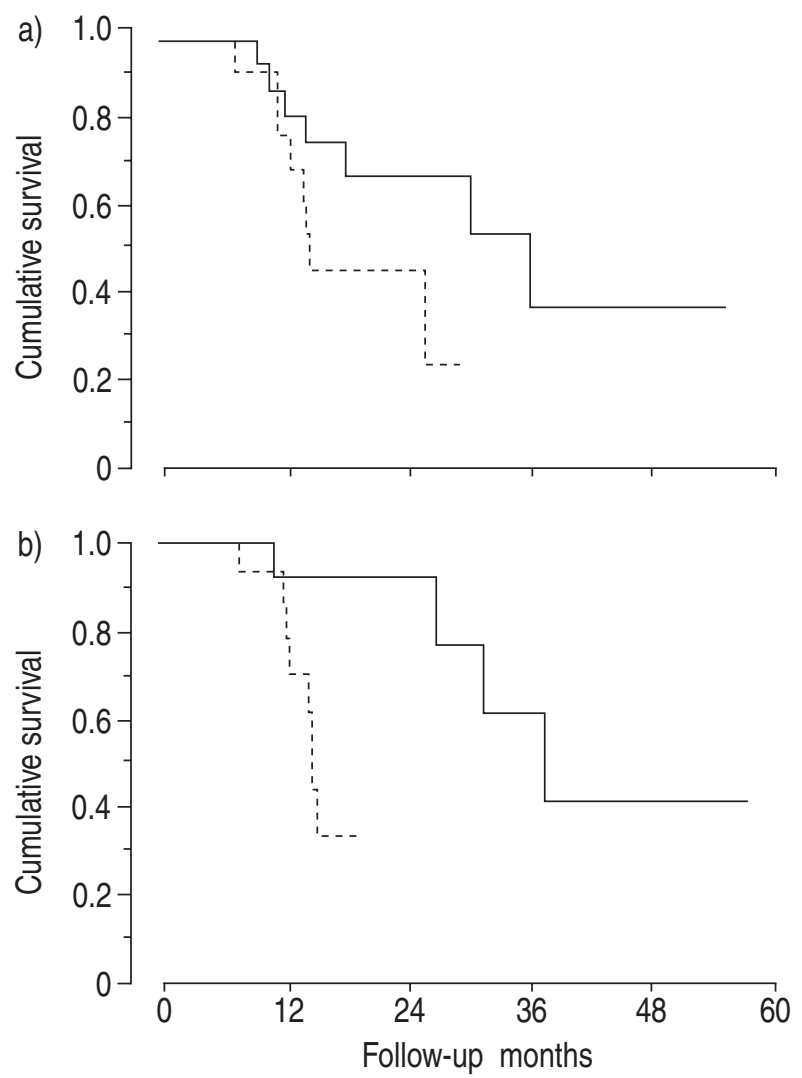

Fig. 2.-Survival according to response assessment after induction chemotherapy in stage IIIA-N2 nonsmall cell lung cancer assessed either on a) computed tomography (CT) (-: overall CT response; - - -: no CT response; log-rank $\mathrm{p}=0.1$ ) or b) ${ }^{18}$ F-fluoro2-deoxy-glucose positron emission tomography (FDG-PET) ( - : overall PET response; - - -: no PET response; log-rank p=0.008) (interim results of ongoing study adapted from [123]).

prognosis after IC. Patients with either presence or absence of downstaging on CT had a similar survival, but there was a significant difference in survival after the entire combined modality treatment between the groups with or without downstaging on FDG-PET $(p=0.01)$. The same finding was present when looking at primary tumour response. No significant difference in survival emerged between patients who had a decrease of the product of the two perpendicular diameters of $>50 \%$ (i.e. response) or not on CT. Looking at FDG-PET response, however, a significant difference in survival between the groups with or without a $50 \%$ decrease in SUV of the primary tumour after IC was noted $(p=0.02)$. One of the possible explanations why FDG-PET response is of considerable importance is that a high SUV after IC means persistence of highly proliferative, probably chemoresistant tumour cells, which could be responsible for the (systemic) relapse after treatment.

These promising initial findings led to the conclusion that FDG-PET had the potential to become a reliable noninvasive technique to assess IC, to select patients for intensive locoregional treatment after IC, and for the initiation of a larger prospective multicentre study.

Interim results of this study have recently been reported at another meeting [123]. Although the accuracy of FDG-PET in assessing downstaging slightly decreased, the value in prediction of prognosis seems to be confirmed, as illustrated in figure 2 . When response on FDG-PET after IC is defined as both mediastinal clearance and a decrease of $>50 \%$ of the SUV of the primary tumour, a highly significant prognostic discrimination is found $(\mathrm{p}=0.008)$. Conversely, CT has only limited value $(\mathrm{p}=0.10)$, as already noted from past experience.

\section{Conclusions and prospects}

FDG-PET, which is complimentary to CT, now has a clinical indication in the diagnosis and staging of NSCLC and reimbursement in an increasing number of European countries for this purpose. A summary of the possible clinical implementation that was suggested by Vansteenkiste and Stroobants [21] in a recent review is depicted in figure 3 . The use of

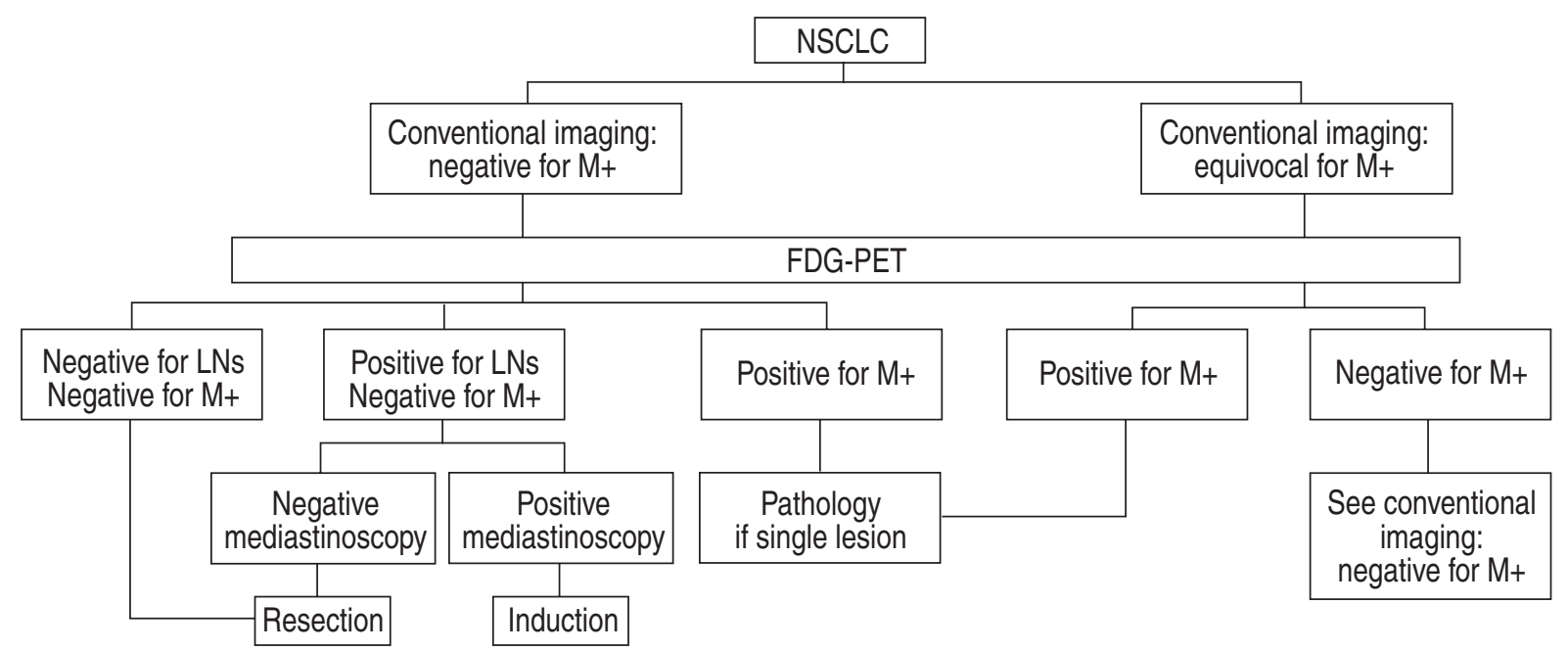

Fig. 3.-Possible implementation of ${ }^{18}$ F-fluoro-2-deoxy-glucose positron emission tomography (FDG-PET) in nonsmall cell lung cancer (NSCLC) management. LN: lymph node; M+: metastasis. 
FDG-PET in these current clinical indications now needs further validation in large-scale multicentre studies, focusing mainly on treatment outcome and cost-efficacy.

Other indications, such as evaluation of radioor chemotherapy, radiotherapy planning, recurrence detection and prognosis determination also need further well-designed prospective investigations, but in more specialized centres.

Finally, a whole new field using molecular probes in positron emission tomography is under exploration. An important number of new tracers is under investigation. It is hoped that positron emission tomography examinations with these molecular tracers will become sufficiently reliable and manageable to evaluate receptors, transport proteins or intracellular enzymes. This is of major importance to assess the large number of novel molecular-targeted lung cancer therapies, which are coming into phase II and III trials now [124].

\begin{abstract}
Acknowledgements. The authors want to thank the numerous other coworkers involved in the ${ }^{18}$ F-fluoro-2-deoxy-glucose positron emission tomography research programme of the Leuven Lung Cancer Group (LLCG) (in alphabetic order): Data-nursing LLCG (B. Anrys, D. Strens), Nuclear Medicine (P. Dupont, L. Mortelmans, S. Stroobants), Pathology (E. Verbeken), Pneumology (M. Demedts, K. Nackaerts), Radiology (J. Bogaert, W. De Wever, J. Verschakelen), Radiotherapy (Y. Lievens, L. Van Uytsel), Thoracic Surgery (P. De Leyn, G. Deneffe, T. Lerut, D. Van Raemdonck).
\end{abstract}

\section{References}

1. Dupont $\mathrm{P}$, Orban G, Vogels $\mathrm{R}$, et al. Different perceptual tasks performed with the same visual stimulus attribute activate different regions of the human brain: a PET study. Proc Nat Acad Science 1993; 90: 10927-10931.

2. Huang SC, Phelps ME, Hoffman EJ, Sideris K, Selin CJ, Kuhl DE. Noninvasive determination of local cerebral metabolic rate of glucose in man. Am J Physiol 1980; 238: E69-E82.

3. Mortelmans L, Vanhaecke J, Lesaffre E, et al. Evaluation of the effect of thrombolytic treatment on infarct size and left ventricular function by enzymatic, scintigraphic and angiographic methods. Am Heart J 1990; 6: 1231-1237.

4. Mortelmans L, Nuyts J, Scheys I, et al. A new quantitative method for the analysis of cardiac perfusion tomography (SPECT). Validation in patients treated with thrombolytic therapy. Eur J Nucl Med 1993; 20: 1193-1200.

5. Warburg O, Posener K, Negelein E. The metabolism of the carcinoma cell. In: Warburg $\mathrm{O}$, ed. The Metabolism of Tumors. New York, Richard R. Smith, Inc., 1931; pp. 129-169.

6. Nolop KB, Rhodes CG, Brudin LH, et al. Glucose utilization in vivo by human pulmonary neoplasms. Cancer 1987; 60: 2682-2689.

7. Nelson CA, Wang JQ, Leav I, Crane PD. The interaction among glucose transport, hexokinase, and glucose-6-phosphatase with respect to $3 \mathrm{H}-2-$ deoxyglucose retention in murine tumor models. Nuclear Medicine \& Biology 1996; 23: 533-541.

8. Yamamoto T, Seino Y, Fukumoto $\mathrm{H}$, et al. Overexpression of facilitative glucose transporter genes in human cancer. Biochem Biophys Res Commun 1990; 170: 223-230.

9. Ido T, Wan C, Carella V, et al. Labeled 2-deoxy-Dglucose analogs: ${ }^{18} \mathrm{~F}$-labeled 2-deoxy-2-fluoro-D-glucose, 2-deoxy-2-fluoro-D-mannose and 14C-2-deoxy-2-fluoroD-glucose. J Label Compds Radiopharm 1978; 24: 174 183.

10. Monakhav NK, Neistadt EL, Showlowskil MM. Physicochemical properties and isoenzyme composition of hexokinase from normal and malignant human tissues. J Natl Cancer Inst 1978; 67: 27-34.

11. Pauwels EK, McCready VR, Stoot JH, van Deurzen DF. The mechanism of accumulation of tumourlocalising radiopharmaceuticals. Eur J Nucl Med 1998; 25: 277-305

12. Wahl R, Hutchins G, Bushsboaum D, Liebert $M$, Grossman H, Fisher S. ${ }^{18}$ F-2-deoxy-2fluoro-D-glucose uptake into human tumor xenografts: feasibility studies for cancer imaging with positron emission tomography. Cancer 1991; 67: 1544-1550.

13. Keyes JW. SUV: standard uptake or silly useless value? J Nucl Med 1995; 36: 1836-1839.

14. Meikle SR, Bailey DL, Hooper PK, et al. Simultaneous emission and transmission measurements for attenuation correction in whole-body PET. $\mathrm{J} \mathrm{Nucl}$ Med 1995; 36: 1680-1688.

15. Hooper PK, Meikle SR, Eberl S, Fulham MJ. Validation of postinjection transmission measurements for attenuation correction in neurological FDG-PET studies. J Nucl Med 1996; 37: 128-136.

16. Coleman RE, Laymon CM, Turkington TG. FDG imaging of lung nodules: a phantom study comparing SPECT, camera-based PET, and dedicated PET. Radiology 1999; 210: 823-828.

17. Tatsumi M, Yutani K, Watanabe Y, et al. Feasibility of fluorodeoxyglucose dual-head gamma camera coincidence imaging in the evaluation of lung cancer: comparison with FDG PET. J Nucl Med 1999; 40: 566-573.

18. Weber WA, Neverve $\mathbf{J}$, Sklarek $\mathbf{J}$, et al. Imaging of lung cancer with fluorine-18 fluorodeoxyglucose: comparison of a dual-head gamma camera in coincidence mode with a full-ring positron emission tomography system. Eur J Nucl Med 1999; 26: 388-395.

19. Lonneux M, Delval D, Bausart R, et al. Can dualheaded ${ }^{18}$ F-FDG SPET imaging reliably supersede PET in clinical oncology? A comparative study in lung and gastrointestinal tract cancer. Nucl Med Commun 1998; 19: 1047-1054.

20. Shreve PD, Steventon RS, Deters EC, Kison PV, Gross MD, Wahl RL. Oncologic diagnosis with 2-[fluorine-18]fluoro-2-deoxy-D-glucose imaging: dualhead coincidence gamma camera versus positron emission tomographic scanner. Radiology 1998; 207: $431-437$.

21. Vansteenkiste JF, Stroobants SG. The role of positron emission tomography with ${ }^{18} \mathrm{~F}$-fluoro-2-deoxy-Dglucose in respiratory oncology. Eur Respir $J$ 2001; 17: 802-820

22. Cummings SR, Lillington GA, Richard RJ. Managing 
solitary pulmonary nodules. The choice of strategy is a "close call". Am Rev Respir Dis 1986; 134: 453-460.

23. Yankelevitz DF, Henschke CI. Does 2-year stability imply that pulmonary nodules are benign? AJR 1997; 168: $325-328$.

24. Santambrogio L, Nosotti M, Bellaviti N, Pavoni G, Radice F, Caputo V. CT-guided fine-needle aspiration cytology of solitary pulmonary nodules: a prospective, randomized study of immediate cytologic evaluation. Chest 1997; 112: 423-425.

25. Larscheid RC, Thorpe PE, Scott WJ. Percutaneous transthoracic needle aspiration biopsy: a comprehensive review of its current role in the diagnosis and treatment of lung tumors. Chest 1998; 114: 704-709.

26. Michiels E, Demedts M. Pitfalls of transthoracic needle aspiration biopsy. Acta Clin Belg 1991; 46: 359-363.

27. Sazon DA, Santiago SM, Soo Hoo GW, et al. Fluorodeoxyglucose-positron emission tomography in the detection and staging of lung cancer. Am J Respir Crit Care Med 1996; 153: 417-421.

28. Lowe VJ, Fletcher JW, Gobar L, et al. Prospective investigation of positron emission tomography in lung nodules. J Clin Oncol 1998; 16: 1075-1084.

29. Duhaylongsod FG, Lowe VJ, Patz EF, Vaughn AL, Coleman RE, Wolfe WG. Detection of primary and recurrent lung cancer by means of F-18 fluorodeoxyglucose positron emission tomography (FDG PET). J Thorac Cardiovasc Surg 1995; 110: 130-139.

30. Nackaerts K, Stroobants S, Vansteenkiste J, et al. The use of positron emission tomography (PET) in the differential diagnosis of indeterminate solitary pulmonary lesions. Eur Respir J 1997; 10: 425s.

31. Patz EF, Lowe VJ, Hoffman JM, et al. Focal pulmonary abnormalities: evaluation with F-18 fluorodeoxyglucose PET scanning. Radiology 1993; 188: 487-490.

32. Bury T, Dowlati A, Paulus P, et al. Evaluation of the solitary pulmonary nodule by positron emission tomography imaging. Eur Respir J 1996; 9: 410-414.

33. Slosman DO, Spiliopoulos A, Couson F, et al. Satellite PET and lung cancer: a prospective study in surgical patients. Nucl Med Commun 1993; 14: 955961.

34. Dewan NA, Gupta NC, Redepenning LS, Phalen JJ, Frick MP. Diagnostic efficacy of PET-FDG imaging in solitary pulmonary nodules. Potential role in evaluation and management. Chest 1993; 104: $997-$ 1002 .

35. Kubota K, Matsuzawa T, Fujiwara T, et al. Differential diagnosis of lung tumor with positron emission tomography: a prospective study. J Nucl Med 1990; 31: 1927-1932.

36. Gupta NC, Frank AR, Dewan NA, et al. Solitary pulmonary nodules: detection of malignancy with PET with 2-[F-18]-fluoro-2-deoxy-D-glucose. Radiology 1992; 184: 441-444.

37. Gupta N, Gill H, Graeber G, Bishop H, Hurst J, Stephens T. Dynamic positron emission tomography with F-18 fluorodeoxyglucose imaging in differentiation of benign from malignant lung/mediastinal lesions. Chest 1998; 114: 1105-1111.

38. Scott WJ, Schwabe JL, Gupta NC, Dewan NA, Reeb SD, Sugimoto JT. Positron emission tomography of lung tumors and mediastinal lymph nodes using [18F]fluorodeoxyglucose. The Members of the PET-Lung
Tumor Study Group. Ann Thorac Surg 1994; 58: 698703.

39. Erasmus JJ, McAdams HP, Patz EF, Coleman RE, Ahuja V, Goodman PC. Evaluation of primary pulmonary carcinoid tumors using FDG PET. AJR 1998; 170: 1369-1373.

40. Higashi K, Nishikawa $\mathrm{T}$, Seki $\mathrm{H}$, et al. Comparison of fluorine-18-FDG PET and thallium-201 SPECT in evaluation of lung cancer. J Nucl Med 1998; 39: 9-15.

41. Higashi K, Ueda Y, Seki $\mathrm{H}$, et al. Fluorine-18-FDG PET imaging is negative in bronchioloalveolar lung carcinoma. J Nucl Med 1998; 39: 1016-1020.

42. Kim BT, Kim Y, Lee KS, et al. Localized form of bronchioloalveolar carcinoma: FDG PET findings. AJR Am J Roentgenol 1998; 170: 935-939.

43. Kapucu LO, Meltzer CC, Townsend DW, Keenan RJ, Luketich JD. Fluorine-18-fluorodeoxyglucose uptake in pneumonia. $J$ Nucl Med 1998; 39: 12671269.

44. Brudin LH, Valind SO, Rhodes CG, et al. Fluorine-18 deoxyglucose uptake in sarcoidosis measured with positron emission tomography. Eur J Nucl Med 1994; 21: 297-305.

45. Bakheet SM, Saleem M, Powe J, Al Amro A, Larsson SG, Mahassin Z. F-18 fluorodeoxyglucose chest uptake in lung inflammation and infection. Clin $\mathrm{Nucl}$ Med 2000; 25: 273-278.

46. Vansteenkiste J, De Leyn P, Deneffe G, et al. Present status of induction treatment for N2 non-small cell lung cancer: a review. Eur J Cardiothorac Surg 1998; 13: $1-12$.

47. Roth J, Fossella F, Komaki RP, et al. A randomized trial comparing perioperative chemotherapy and surgery with surgery alone in resectable stage IIIA non small cell lung cancer. J Natl Cancer Inst 1994; 86: 673-680.

48. Rosell R, Gomez Codina J, Camps C, et al. A randomized trial comparing preoperative chemotherapy plus surgery with surgery alone in patients with non-small-cell lung cancer. N Engl J Med 1994; 330: 153-158.

49. Pass HI, Pogrebniak HW, Steinberg SM, Mulshine J, Minna J. Randomized trial of neoadjuvant therapy for lung cancer: interim analysis. Ann Thorac Surg 1992; 53: 992-998.

50. Splinter TA, Kirckpatrick A, Van Meerbeeck J, et al. Randomized trial of surgery versus radiotherapy in patients with stage IIIA non-small cell lung cancer after a response to induction-chemotherapy. Intergroup study 08941. Proc Am Soc Clin Oncol 1998; 17: 453A.

51. McLoud TC, Bourgouin PM, Greenberg RW, et al. Bronchogenic carcinoma: analysis of staging in the mediastinum with $\mathrm{CT}$ by correlative lymph node mapping and sampling. Radiology 1992; 182: 319-323.

52. Staples CA, Miller RR, Evans KG, Nelems B. Mediastinal nodes in bronchogenic carcinoma: comparison between CT and mediastinoscopy. Radiology 1988; 167: 367-372.

53. Martini N, Heelan R, Westcott J, et al. Comparative merits of conventional, computed tomographic, and magnetic resonance imaging in assessing mediastinal involvement in surgically confirmed lung carcinoma. J Thorac Cardiovasc Surg 1985; 90: 639-648.

54. Gdeedo A, Van Schil P, Corthouts B, Van Mieghem F, Van Meerbeeck J, Van Marck E. Prospective 
evaluation of computed tomography and mediastinoscopy in mediastinal lymph node staging. Eur Respir $J$ 1997; 10: 1547-1551.

55. Webb WR, Gatsouris S, Zerhouni EA, et al. CT and MR imaging in staging non-small cell bronchogenic carcinoma: report of the Radiology Diagnostic Oncology Group. Radiology 1991; 178: 705-713.

56. Dillemans B, Deneffe G, Verschakelen J, Decramer M. Value of computed tomography and mediastinoscopy in preoperative evaluation of mediastinal nodes in non-small cell lung cancer. Eur J Cardiothorac Surg 1994; 8: 37-42.

57. Saunders CA, Dussek JE, O'Doherty MJ, Maisey MN. Evaluation of fluorine-18-fluorodeoxyglucose whole body positron emission tomography imaging in the staging of lung cancer. Ann Thorac Surg 1999; 67: 790-797.

58. Valk PE, Pounds TR, Hopkins DM, et al. Staging non-small cell lung cancer by whole-body positron emission tomographic imaging. Ann Thorac Surg 1995; 60: 1573-1581.

59. Vansteenkiste JF, Stroobants SG, De Leyn PR, et al. Lymph node staging in non-small cell lung cancer with FDG-PET scan: A prospective study on 690 lymph node stations from 68 patients. J Clin Oncol 1998; 16: 2142-2149.

60. Kernstine KH, Stanford W, Mullan BF, et al. PET, $\mathrm{CT}$, and MRI with Combidex for mediastinal staging in non-small cell lung carcinoma. Ann Thorac Surg 1999; 68: 1022-1028.

61. Vansteenkiste JF, Stroobants SG, Dupont PJ, et al. FDG-PET scan in potentially operable non-small cell lung cancer: do anatometabolic PET-CT fusion images improve the localisation of regional lymph node metastases? Eur J Nucl Med 1998; 25: 1495-1501.

62. Vansteenkiste JF, Stroobants SG, De Leyn PR, et al. Mediastinal lymph node staging with FDG-PET scan in patients with potentially operable non-small cell lung cancer: a prospective analysis of 50 cases. Chest 1997; 112: 1480-1486.

63. Bury T, Paulus P, Dowlati A, et al. Staging of the mediastinum: value of positron emission tomography imaging in non-small cell lung cancer. Eur Respir $J$ 1996; 9: 2560-2564.

64. Weng E, Tran L, Rege S, et al. Accuracy and clinical impact of mediastinal lymph node staging with FDGPET imaging in potentially resectable lung cancer. Am J Clin Oncol 2000; 23: 47-52.

65. Steinert HC, Hauser M, Allemann F, et al. Non-small cell lung cancer: nodal staging with FDG PET versus CT with correlative lymph node mapping and sampling. Radiology 1997; 202: 441-446.

66. Patz EF, Lowe VJ, Goodman PC, Herndon J. Thoracic nodal staging with PET imaging with 18 FDG in patients with bronchogenic carcinoma. Chest 1995; 108: 1617-1621.

67. Chin R, Ward R, Keyes JW, et al. Mediastinal staging of non-small-cell lung cancer with positron emission tomography. Am J Respir Crit Care Med 1995; 152: 2090-2096.

68. Scott WJ, Gobar LS, Terry JD, Dewan NA, Sunderland JJ. Mediastinal lymph node staging of non-small-cell lung cancer: a prospective comparison of computed tomography and positron emission tomography. J Thorac Cardiovasc Surg 1996; 111: 642-648.

69. Albes JM, Lietzenmayer R, Schott U, Schulen E, Wehrmann M, Ziemer G. Improvement of non-smallcell lung cancer staging by means of positron emission tomography. Thorac Cardiovasc Surgeon 1999; 47: 4247.

70. Wahl RL, Quint LE, Greenough RL, Meyer CR, White RI, Orringer MB. Staging of mediastinal nonsmall cell lung cancer with FDG PET, CT, and fusion images: preliminary prospective evaluation. Radiology 1994; 191: 371-377.

71. Berlangieri SU, Scott AM, Knight SR, et al. F-18 fluorodeoxyglucose positron emission tomography in the non-invasive staging of non-small cell lung cancer. Eur J Cardiothorac Surg 1999; 16: Suppl. 1, S25-S30.

72. Sasaki M, Ichiya Y, Kuwabara Y, et al. The usefulness of FDG positron emission tomography for the detection of mediastinal lymph node metastases in patients with non-small cell lung cancer: a comparative study with X-ray computed tomography. Eur J Nucl Med 1996; 23: 741-747.

73. Vansteenkiste JF, De Leyn PR, Deneffe GJ, et al. Survival and prognostic factors in resected N2 nonsmall cell lung cancer: A study of 140 cases. The Leuven Lung Cancer Group. Ann Thorac Surg 1997; 63: 1441-1450.

74. ATS Guidelines. Pretreatment evaluation of non-small cell lung cancer. The American Thoracic Society and The European Respiratory Society. Am J Respir Crit Care Med 1997; 156: 320-332.

75. Goldstraw P, Rocmans P, Ball D, et al. Pretreatment minimal staging for non-small cell lung cancer: an updated consensus report. Lung Cancer 1994; 11: Suppl. 3, 1-4.

76. Martini N, Bains MS, Burt ME, et al. Incidence of local recurrence and second primary tumors in resected stage I lung cancer. $J$ Thorac Cardiovasc Surg 1995; 109: 120-129.

77. Pairolero PC, Williams DE, Bergstralh EJ, Piehler JM, Bernatz PE, Payne WS. Postsurgical stage I bronchogenic carcinoma: morbid implications of recurrent disease. Ann Thorac Surg 1984; 38: 331-338.

78. Yano $\mathrm{T}$, Yokoyama $\mathrm{H}$, Inoue $\mathrm{T}$, et al. The first site of recurrence after complete resection in non-small cell carcinoma of the lung. Comparison between $\mathrm{pN} 0$ disease and $\mathrm{pN} 2$ disease. $J$ Thorac Cardiovasc Surg 1994; 108: 680-683.

79. Pantel K, Izbicki J, Passlick B, et al. Frequency and prognostic significance of isolated tumour cells in bone marrow of patients with non-small cell lung cancer without overt metastases. Lancet 1996; 347: 649-653.

80. Quint LE, Tummala S, Brisson LJ, et al. Distribution of distant metastases from newly diagnosed non-small cell lung cancer. Ann Thorac Surg 1996; 62: 246-250.

81. Bury T, Barreto A, Daenen F, Barthelemy N, Ghaye B, Rigo P. Fluorine-18 deoxyglucose positron emission tomography for the detection of bone metastases in patients with non-small cell lung cancer. Eur J Nucl Med 1998; 25: 1244-1247.

82. Schirrmeister $\mathrm{H}$, Guhlmann A, Elsner $\mathrm{K}$, et al. Sensitivity in detecting osseous lesions depends on anatomic localization: planar bone scintigraphy versus 18F-PET. J Nucl Med 1999; 40: 1623-1629.

83. Oliver TW, Bernardino ME, Miller JI, Mansour K, Greene D, Davis WA. Isolated adrenal masses in non-small cell bronchogenic carcinoma. Radiology 1984; 153: 217-218.

84. Nielsen ME, Heaston DK, Dunnick NR, Korobkin M. Preoperative CT evaluation of adrenal glands in non-small cell bronchogenic carcinoma. AJR 1982; 139: $317-320$. 
85. Pagani JJ. Non-small cell lung carcinoma adrenal metastases. Computed tomography and percutaneous needle biopsy in their diagnosis. Cancer 1984; 53: 1058-1060.

86. Erasmus JJ, Patz EF, McAdams HP, et al. Evaluation of adrenal masses in patients with bronchogenic carcinoma using $18 \mathrm{~F}$-fluorodeoxyglucose positron emission tomography. AJR Am J Roentgenol 1997; 168: 1357-1360.

87. Boland GW, Goldberg MA, Lee MJ, et al. Indeterminate adrenal mass in patients with cancer: evaluation at PET with 2-[F-18]-fluoro-2-deoxy-D-glucose. Radiology 1995; 194: 131-134.

88. Maurea S, Mainolfi C, Bazzicalupo L, et al. Imaging of adrenal tumors using FDG PET: comparison of benign and malignant lesions. AJR 1999; 173: 25-29.

89. Hustinx R, Paulus P, Jacquet N, Jerusalem G, Bury $\mathrm{T}$, Rigo P. Clinical evaluation of whole-body $18 \mathrm{~F}-$ fluorodeoxyglucose positron emission tomography in the detection of liver metastases. Ann Oncol 1998; 9: 397-401.

90. Marom EM, McAdams HP, Erasmus JJ, et al. Staging non-small cell lung cancer with whole-body PET. Radiology 1999; 212: 803-809.

91. Weder W, Schmid RA, Bruchhaus H, Hillinger S, von Schulthess GK, Steinert HC. Detection of extrathoracic metastases by positron emission tomography in lung cancer. Ann Thorac Surg 1998; 66: 886-892.

92. Bury T, Dowlati A, Paulus P, Hustinx R, Radermecker M, Rigo P. Staging of non-small cell lung cancer by whole-body fluorine- 18 deoxyglucose positron emission tomography. Eur J Nucl Med 1996; 23: 204-206.

93. Lewis $\mathrm{P}$, Griffin $\mathrm{S}$, Marsden $\mathrm{P}$, et al. Whole-body $18 \mathrm{~F}$ fluorodeoxyglucose positron emission tomography in preoperative evaluation of lung cancer. Lancet 1994; 344: 1265-1266.

94. Graham MV, Purdy JA, Emami B, Matthews JW, Harms WB. Preliminary results of a prospective trial using three dimensional radiotherapy for lung cancer. Int J Radiat Oncol Biol Phys 1995; 33: 993-1000.

95. Kwa SL, Lebesque JV, Theuws JC, et al. Radiation pneumonitis as a function of mean lung dose: an analysis of pooled data of 540 patients. Int $J$ Radiat Oncol Biol Phys 1998; 42: 1-9.

96. Marks LB, Munley MT, Bentel GC, et al. Physical and biological predictors of changes in whole-lung function following thoracic irradiation. Int $J$ Radiat Oncol Biol Phys 1997; 39: 563-570.

97. Martel MK, Ten Haken RK, Hazuka MB, Turrisi AT, Fraass BA, Lichter AS. Dose-volume histogram and 3-D treatment planning evaluation of patients with pneumonitis. Int J Radiat Oncol Biol Phys 1994; 28: 575-581.

98. Graham MV. Predicting radiation response. Int J Radiat Oncol Biol Phys 1997; 39: 561-562.

99. Robertson JM, Ten Haken RK, Hazuka MB, et al. Dose escalation for non-small cell lung cancer using conformal radiation therapy. Int $J$ Radiat Oncol Biol Phys 1997; 37: 1079-1085.

100. Hebert ME, Lowe VJ, Hoffman JM, Patz EF, Anscher MS. Positron emission tomography in the pretreatment evaluation and follow-up of non-small cell lung cancer patients treated with radiotherapy: preliminary findings. Am J Clin Oncol 1996; 19: 416421.

101. Nestle U, Walter K, Schmidt S, et al. 18F-deoxyglucose positron emission tomography (FDG-PET) for the planning of radiotherapy in lung cancer: high impact in patients with atelectasis. Int J Radiat Oncol Biol Phys 1999; 44: 593-597.

102. Vanuytsel LJ, Vansteenkiste JF, Stroobants SG, et al. The impact of (18)F-fluoro-2-deoxy-D-glucose positron emission tomography (FDG-PET) lymph node staging on the radiation treatment volumes in patients with non-small cell lung cancer. Radiother Oncol 2000; 55: 317-324.

103. Cai J, Chu JC, Recine D, et al. CT and PET lung image registration and fusion in radiotherapy treatment planning using the chamfer-matching method. Int J Radiat Oncol Biol Phys 1999; 43: 883-891.

104. Giraud P, Grahek D, Montravers F, et al. CT and (18)F-deoxyglucose (FDG) image fusion for optimization of conformal radiotherapy of lung cancers. Int J Radiat Oncol Biol Phys 2001; 49: 1249-1257.

105. Munley MT, Marks LB, Scarfone C, et al. Multimodality nuclear medicine imaging in three-dimensional radiation treatment planning for lung cancer: challenges and prospects. Lung Cancer 1999; 23: 105-114.

106. Kiffer JD, Berlangieri SU, Scott AM, et al. The contribution of $18 \mathrm{~F}$-fluoro-2-deoxy-glucose positron emission tomographic imaging to radiotherapy planning in lung cancer. Lung Cancer 1998; 19: 167177.

107. Graham MV, Purdy JA. Regarding predicting radiation response. In response to Dr. Lawrence et al. Int J Radiat Oncol Biol Phys 1998; 41: 972-973.

108. Johnson DH, Einhorn LH, Bartolucci A, et al. Thoracic radiotherapy does not prolong survival in patients with locally advanced, unresectable non-small cell lung cancer. Ann Intern Med 1990; 113: 33-38.

109. Martini N, Flehinger B, Flehinger BJ. The role of surgery in N2 lung cancer. Surg Clin North Am 1987; 67: 1037-1049.

110. Pearson F, DeLarue N, Ilves R, Todd T, Cooper J. Significance of positive superior mediastinal nodes identified at mediastinoscopy in patients with resectable cancer of the lung. $J$ Thorac Cardiovasc Surg 1982; 83: 1-11.

111. Kumar P, Herndon J, Langer M, et al. Patterns of disease failure after trimodality therapy of non-small cell lung carcinoma pathologic stage IIIA (N2). Cancer 1996; 77: 2393-2399.

112. Arriagada R. Optimizing chemotherapy and radiotherapy in locally advanced non-small cell lung cancer. Hematol Oncol Clin North Am 1997; 11: 461-472.

113. Martini N, Kris MG, Flehinger B, et al. Preoperative chemotherapy for stage IIIa (N2) lung cancer: the Sloan-Kettering experience with 136 patients. Ann Thorac Surg 1993; 55: 1365-1374.

114. Albain KS, Rusch VW, Crowley JJ, et al. Concurrent cisplatin/etoposide plus chest radiotherapy followed by surgery for stages IIIA (N2) and IIIB non-smallcell lung cancer: mature results of Southwest Oncology Group phase II study 8805. J Clin Oncol 1995; 13: $1880-1892$.

115. Rice TW, Adelstein DJ, Koka A, et al. Accelerated induction therapy and resection for poor prognosis stage III non-small cell lung cancer. Ann Thorac Surg 1995; 60: 586-591.

116. Weitberg AB, Yashar J, Glicksman AS, et al. Combined modality therapy for stage IIIA non-small cell carcinoma of the lung. Eur J Cancer 1993; 29A: 511515 . 
117. Strauss GM, Herndon JE, Sherman DD, et al. Neoadjuvant chemotherapy and radiotherapy followed by surgery in stage IIIA non-small-cell carcinoma of the lung: report of a Cancer and Leukemia Group B phase II study. J Clin Oncol 1992; 10: 12371244.

118. Choi NC, Carey RW, Daly W, et al. Potential impact on survival of improved tumor downstaging and resection rate by preoperative twice-daily radiation and concurrent chemotherapy in stage IIIA non-small-cell lung cancer. J Clin Oncol 1997; 15: 712-722.

119. Pisters KM, Kris MG, Gralla RJ, Zaman MB, Heelan RT, Martini N. Pathologic complete response in advanced non-small-cell lung cancer following preoperative chemotherapy: implications for the design of future non-small-cell lung cancer combined modality trials. J Clin Oncol 1993; 11: $1757-$ 1762.

120. Vansteenkiste JF, Stroobants SG, De Leyn PR, et al. Potential use of FDG-PET scan after induction chemotherapy in surgically staged IIIA-N2 non-small cell lung cancer: a prospective pilot study. Ann Oncol 1998; 9: 1193-1198.

121. Vansteenkiste JF, De Leyn PR, Deneffe GJ, et al. Vindesine-Ifosfamide-Platinum (VIP) induction chemotherapy in surgically staged IIIA-N2 non-small cell lung cancer: a prospective study. Ann Oncol 1998; 9: 261-267.

122. Miller AB, Hoogstraten B, Staquet M, Winkler A. Reporting results of cancer treatment. Cancer 1981; 47: 207-214

123. Vansteenkiste J, Stroobants S, Hoekstra C, et al. 18fluoro-2-deoxyglucose positron emission tomography (PET) in the assessment of induction chemotherapy (IC) in stage IIIA-N2 NSCLC: a multi-center prospective study. Proc Am Soc Clin Oncol 2001; 20: 313A.

124. Price $\mathrm{P}$, Jones T. Can positron emission tomography (PET) be used to detect subclinical response to cancer therapy? The EC PET Oncology Concerted Action and the EORTC PET Study Group. Eur $J$ Cancer 1995; 31A: 1924-1927. 